\title{
Katetuotot syysviljakierrossa
}

\author{
Antti Laine ${ }^{1)}$ ja Marjo Keskitalo ${ }^{2)}$ \\ ${ }^{1)}$ MTT Kasvintuotannon tutkimus, 21500 Piikkiö, antti.laine@mtt.fi \\ ${ }^{2)}$ MTT Kasvintuotannon tutkimus, 31600 Jokioinen, marjo.keskitalo@mtt.fi
}

\section{Tiivistelmä}

MTT:n Piikkiön Yltöisiin perustettiin 2009 viisivuotinen syysviljapainotteinen viljelykiertokoe, jonka tavoitteena on löytää hyötyjä tuottavia viljelykiertoja sekä tehokkaan viljelyn että vesistön lähellä sijaitseville tiloille. Koejärjestelyllä pyritään selvittämään, onko pelkästään syyskylvettävien kasvien viljelykierto mahdollista ja ovatko viljelyriskit pienempiä, sekä hallitusta ravinnekierrosta johtuen ympäristöhyödyt suurempia, kuin kevätkylvöisellä vehnällä ilmaston ja muiden tuotanto-olojen muuttuessa. Koesarjassa verrataan myös syyskylvöisten talvituhoja kevätkylvöisten kevätkuivuuden aiheuttamiin satotappioihin 5 vuoden aikana. Tuotannon kannattavuutta seurataan katetuottomenetelmiin perustuvin laskelmin.

\section{Viljelykierrot}

Viljelykierroiksi valittiin kaksi erilaista kiertoa, ensimmäiseen kierron tavoitteena on kehittää ensisijaisesti syysvehnän viljelykiertoa, jossa mukaan tulevat öljykasvit ja aluskasvit, tarkoituksena vähentää kevätkuivuuden aiheuttamia satotappioita. Toiseksi viljelykierroksi valittiin monipuolinen viljelykierto, jossa huomioitiin myös talviaikainen maanpeitteisyysvaatimus ympäristötukeen oikeuttavilla kasveilla. Koetta perustettaessa 2009, syysvehnää ei vielä hyväksytty kasvipeitteisyysvaatimusta täyttäväksi, kuten vuoden 2010 syksystä lähtien, oli mukaan saatava talviaikaiseen kasvipeitteisyyteen hyväksyttäviä kasveja kuten heinä ja apilakasveja, joilla peitettiin $25-50 \%$ koko alasta. Viljasatoa tuottavia vuosia kierrossa on vain kolmena vuotena neljästä. Vertailuun otettiin mukaan sekä syysviljan että kevätviljan monokulttuuri, joista selviävät sekä viljelykierron, että syysmuotojen hyödyt.

\section{Tuotannon kannattavuus}

Työvaiheet ja niihin kulutettu aika ja viljelytoimenpiteet, kuten muokkauskerrat, lannoitteet, kylvösiemen, torjunta-aineet, puintikosteus, sato ja tuotteiden hinnat kirjattiin ylös, jotta niiden avulla voitiin arvioida viljelykiertojen viljelykustannuksia. Viljojen hintavaihtelut ovat olleet suuria sekä maailmalla että Suomessa viime vuosina. Suomessa viljan ostojen hintanoteeraukset ovat kulkeneet maailman viljapörssien hintoja selkeästi alemmalla tasolla. Lannoitteiden hinnat ovat seuranneet kohoavia viljanhintoja. Eri vuosien välisessä kannattavuuden seurannassa ostojen ja myyntien ajoituksella on siten suuri merkitys kiertojen välisen kannattavuuden vertailuun.

Kolmen koevuoden jälkeen yksipuolisen syysvehnän viljelyn kate A oli syysvehnällä $2 \%$ parempi kevätvehnän monokulttuuria. Syysviljojen paremman kuivuuden kestävyyden johdosta syysvehnän satotasot ovat kevätvehnien satoa korkeampia. Korkeammasta satotasosta johtuen syysvehnän valkuaispitoisuus jää alle myllyvehnien laatuvaatimuksia kevätvehniä useammin. Vuoden 2011 vehnäsadosta sekä syys-, että kevätvehnän hehtolitrapainot eivät ylittäneet hehtolitrapainon osalta myllyvehnän laatua. Katetuottojen tarkasteluajankohtana pidettiin vuosittain vuoden vaihteen seutua. Kiertoon 1 kuuluvien koejäsenten 1-4 keskimääräinen kate A oli $9 \%$ pienempi ja kiertoon 2 kuluvien koejäsenten 5-8 kate A $7 \%$ pienempi jatkuvan syysvehnäkierron kolmen vuoden yhteenlasketuista katetuotoista. Vuoden 2011 satotulosten perusteella syysvehnän jatkuva viljely alkoi näkyä satotulosten heikkenemisenä, syysvehnäsato jäi 1000 $2200 \mathrm{~kg} / \mathrm{ha}$ pienemmäksi jatkuvassa syysvehnän viljelyssä verrattuna kiertoviljelyyn. Koska koesarjassa ei ole vielä umpeutunut viiden vuoden kierto ja satotasot eivät ole hakeutuneet vielä kohdilleen, tulevat vasta koesarjan viimeiset vuodet osoittamaan järjestelmien väliset todelliset erot. 


\section{Johdanto}

MTT:n Piikkiön Yltöisiin perustettiin 2009 viisivuotinen syysviljapainotteinen viljelykiertokoe, jonka tavoitteena on löytää hyötyjä tuottavia viljelykiertoja sekä tehokkaan viljelyn että vesistön lähellä sijaitseville tiloille. Koejärjestelyllä pyritään selvittämään, onko pelkästään syyskylvettävien kasvien viljelykierto mahdollista ja ovatko viljelyriskit pienempiä, sekä hallitusta ravinnekierrosta johtuen ympäristöhyödyt suurempia, kuin kevätkylvöisellä vehnällä ilmaston ja muiden tuotanto-olojen muuttuessa. Koesarjassa verrataan myös syyskylvöisten talvituhoja kevätkylvöisten kevätkuivuuden aiheuttamiin satotappioihin 5 vuoden aikana. Tuotannon kannattavuutta seurataan katetuottomenetelmiin perustuvin laskelmin.

\section{Aineisto ja menetelmät}

Koe alkoi vuoden 2009 keväällä ja se perustettiin kevätvehnällä, kevätrypsillä, herneellä ja aluskasveilla (Taulukko 1.). Kaikki kylvöt tehtiin etulautasmuokkaimella varustetulla Tume Nova suorakylvökoneella. Kevätvehnällä kylvösiemenenä käytettiin Kruunua 230 kg/ha, herneellä Karitaa 422 $\mathrm{kg} / \mathrm{ha}$ ja kevätrypsillä Apolloa $8 \mathrm{~kg} / \mathrm{ha}$. Lannoituksena käytettiin kevätvehnälle ja -rypsille Kevätviljan Y 1 (26-2-3) $500 \mathrm{~kg} / \mathrm{ha}$ ja herneelle $154 \mathrm{~kg} / \mathrm{ha}$. Rikkakasvin torjuntaan käytettiin puhtailla kevätvehnäkasvustoilla Express 50T 2 tablettia/ha sekä Starane 180 0,8 1/ha. Apilaa aluskasvina sisältäville kevätvehnille rikkakasvien torjuntana Express 50T 1 tabletti/ha + MCPA-neste 0,5 1/ha. Herneen rikkakasvin torjunnassa Senkor $0,2 \mathrm{~kg} / \mathrm{ha}$. Kevätrypsikasvustoista torjuttiin kirpat ja kuoriaiset kolmeen kertaan Karate $2.5 \mathrm{WG}$ valmisteella $0,15 \mathrm{~kg} / \mathrm{ha}$ ainemäärällä. Urho syysvehnä kylvettiin syksyllä 2009247 $\mathrm{kg} / \mathrm{ha}$ kevätvehnän, herneen ja kevätrypsin jälkeen ilman syyslannoitusta myöhäisen kylvöajankohdan johdosta (22.9.2009).

Vuoden 2010 keväällä kylvettiin puna-apila $4 \mathrm{~kg} / \mathrm{ha}$ ja rainata $9 \mathrm{~kg} / \mathrm{ha}$ syysvehnäruuduille. Syysvehnän lannoituksessa käytettiin Pellon Y 1 (26-2-3) $462 \mathrm{~kg} / \mathrm{ha}$ ja ruuduilla joilla syysvehnän aluskasviksi oli kylvetty puna-apilaa $400 \mathrm{~kg} / \mathrm{ha}$. Kruunu kevätvehnällä kylvömäärä oli $243 \mathrm{~kg} / \mathrm{ha} \mathrm{ja} \mathrm{lannoitus}$ Pellon Y1 500 kg/ha. Hulda herneellä kylvömäärä 348 kg/ha ja lannoituksena Pellon Y1 160 kg/ha. Apollo kevätrypsillä kylvömäärä $9 \mathrm{~kg} / \mathrm{ha}$ ja lannoitus Pellon Y1 $500 \mathrm{~kg} / \mathrm{ha}$. Rikkakasvin torjunnassa apilaa aluskasvina olevilla ruuduilla käytettiin Basagran -MCPA valmistetta 4 1/ha , pelkällä syysvehnällä Logran 20WG $20 \mathrm{~g} / \mathrm{ha}+$ Starane 180 0,5 1/ha. Kevätvehnällä Logran $20 \mathrm{WG} 20 \mathrm{~g} / \mathrm{ha}+$ Starane 180 0,5 1/ha+ kiinnite 0,1 1/ha. Syksyllä 2010 kylvettiin suunnitelmassa olleille koejäsenille Urho syysvehnää $247 \mathrm{~kg} / \mathrm{ha}$ lannoituksena Pellon Y6 (17-5-13) $180 \mathrm{~kg} / \mathrm{ha}$.

Vuonna 2011 syysvehnäruudut lannoitettiin keväällä Suomensalpietarilla (27-0-1) 444 kg/ha. Syysvehnän rikkakasvin torjunnassa Express 50T 1,5 tablettia/ha. Kruunu kevätvehnällä kylvömäärä 261 $\mathrm{kg} / \mathrm{ha}$ ja lannoituksena YaraMila NK1 (25-0-7) $520 \mathrm{~kg} / \mathrm{ha}$, Rikkakasvintorjuntaa Express 50T 1,5 tablettia/ha sekä Starane180. Apollo kevätrypsillä kylvömäärä $9 \mathrm{~kg} / \mathrm{ha}$ ja lannoituksena YaraMila NK1 $520 \mathrm{~kg} / \mathrm{ha}$, rikkakasvien torjuntaan Targa Super 5EC 2,0 1/ha+ kiinnite. Kevätrypsin tuhoeläinten torjuntaan kolmeen kertaan Karate 2.5WG 0,15kg/ha. Hulda herneellä kylvömäärä $323 \mathrm{~kg} / \mathrm{ha}$ ja lannoitus YaraMila NK1 160 $\mathrm{kg} / \mathrm{ha}$. Herneen rikkakasvien torjuntaan käytettiin Basagran SG 0,5 kg/ha ja Fenix 1,0 1/ha.

Katetuottojen laskennassa käytettiin kunkin koevuoden vuoden vaihteessa vallinneita viljan hintoja. Lannoitteissa käytettiin koevuoden alkuvuoden hinnoittelua ja kasvinsuojeluaineiden hintoina kunkin koevuoden Peltokasvien kasvinsuojelu-oppaassa olleita hehtaarikustannuksia kyseisille valmisteille. Työajoille käytettiin menetelmien mukaisia normityöaikoja. 
Taulukko 1. Viljelykierrot syysviljapainotteisessa viljelykiertokokeessa. Kierto 1 aluskasveja hyödyntäen 1-4.

\begin{tabular}{|c|c|c|c|c|c|c|c|c|c|c|c|}
\hline & \multicolumn{2}{|l|}{2009} & \multicolumn{2}{|l|}{2010} & \multicolumn{2}{|l|}{2011} & \multicolumn{2}{|l|}{2012} & \multicolumn{2}{|l|}{2013} & \\
\hline & kevät & syksy & kevät & syksy & kevät & syksy & kevät & syksy & kevät & syksy & \\
\hline 1 & $\begin{array}{l}\text { kevät- } \\
\text { vehnä }\end{array}$ & sänki & $\begin{array}{l}\text { kevät- } \\
\text { rypsi }\end{array}$ & $\begin{array}{l}\text { syys- } \\
\text { vehnä }\end{array}$ & $\begin{array}{l}\text { syys- } \\
\text { vehnä } \\
\text { +puna- } \\
\text { apila } \\
\text { +rainata }\end{array}$ & $\begin{array}{l}\text { puna- } \\
\text { apila }\end{array}$ & $\begin{array}{l}\text { puna- } \\
\text { apila }\end{array}$ & $\begin{array}{l}\text { syys- } \\
\text { vehnä }\end{array}$ & $\begin{array}{l}\text { syys- } \\
\text { vehnä }\end{array}$ & $\begin{array}{l}\text { syys- } \\
\text { vehnä }\end{array}$ & $\begin{array}{l}\text { syys- } \\
\text { vehnä }\end{array}$ \\
\hline 2 & $\begin{array}{l}\text { kevät- } \\
\text { vehnä }\end{array}$ & $\begin{array}{l}\text { syys- } \\
\text { vehnä }\end{array}$ & $\begin{array}{l}\text { syys- } \\
\text { vehnä }\end{array}$ & sänki & $\begin{array}{l}\text { kevät- } \\
\text { rypsi }\end{array}$ & $\begin{array}{l}\text { syys- } \\
\text { vehnä }\end{array}$ & $\begin{array}{l}\text { syys- } \\
\text { vehnä } \\
\text { +puna- } \\
\text { apila } \\
\end{array}$ & $\begin{array}{l}\text { puna- } \\
\text { apila }\end{array}$ & $\begin{array}{l}\text { puna- } \\
\text { apila }\end{array}$ & $\begin{array}{l}\text { syys- } \\
\text { vehnä }\end{array}$ & $\begin{array}{l}\text { syys- } \\
\text { vehnä }\end{array}$ \\
\hline 3 & $\begin{array}{l}\text { kevät- } \\
\text { vehnä } \\
\text { +puna- } \\
\text { apila }\end{array}$ & $\begin{array}{l}\text { puna- } \\
\text { apila }\end{array}$ & $\begin{array}{l}\text { puna- } \\
\text { apila }\end{array}$ & $\begin{array}{l}\text { syys- } \\
\text { vehnä }\end{array}$ & $\begin{array}{l}\text { syys- } \\
\text { vehnä }\end{array}$ & sänki & $\begin{array}{l}\text { kevät- } \\
\text { rypsi }\end{array}$ & $\begin{array}{l}\text { syys- } \\
\text { vehnä }\end{array}$ & $\begin{array}{l}\text { syys- } \\
\text { vehnä } \\
\text { +puna- } \\
\text { apila } \\
\end{array}$ & $\begin{array}{l}\text { puna- } \\
\text { apila }\end{array}$ & $\begin{array}{l}\text { puna- } \\
\text { apila }\end{array}$ \\
\hline 4 & $\begin{array}{l}\text { kevät- } \\
\text { vehnä }\end{array}$ & $\begin{array}{l}\text { syys- } \\
\text { vehnä }\end{array}$ & $\begin{array}{l}\text { syys- } \\
\text { vehnä } \\
\text { +puna- } \\
\text { apila }\end{array}$ & $\begin{array}{l}\text { puna- } \\
\text { apila } \\
\text { +rainata }\end{array}$ & puna-apila & $\begin{array}{l}\text { syys- } \\
\text { vehnä }\end{array}$ & $\begin{array}{l}\text { syys- } \\
\text { vehnä }\end{array}$ & sänki & $\begin{array}{l}\text { kevät- } \\
\text { rypsi }\end{array}$ & $\begin{array}{l}\text { syys- } \\
\text { vehnä }\end{array}$ & $\begin{array}{l}\text { syys- } \\
\text { vehnä } \\
\text { +puna- } \\
\text { apila } \\
\end{array}$ \\
\hline 5 & herne & $\begin{array}{l}\text { syys- } \\
\text { vehnä }\end{array}$ & $\begin{array}{l}\text { syys- } \\
\text { vehnä } \\
\text { +puna- } \\
\text { apila }\end{array}$ & $\begin{array}{l}\text { puna- } \\
\text { apila }\end{array}$ & $\begin{array}{l}\text { kevät- } \\
\text { rypsi }\end{array}$ & $\begin{array}{l}\text { syys- } \\
\text { vehnä }\end{array}$ & $\begin{array}{l}\text { syys- } \\
\text { vehnä } \\
\text { +puna- } \\
\text { apila }\end{array}$ & $\begin{array}{l}\text { puna- } \\
\text { apila }\end{array}$ & $\begin{array}{l}\text { kevät- } \\
\text { vehnä } \\
\text { +rainata }\end{array}$ & rainata & herne \\
\hline 6 & $\begin{array}{l}\text { kevät- } \\
\text { vehnä } \\
\text { +rainata }\end{array}$ & rainata & herne & $\begin{array}{l}\text { syys- } \\
\text { vehnä }\end{array}$ & $\begin{array}{l}\text { syys- } \\
\text { vehnä } \\
\text { +puna- } \\
\text { apila }\end{array}$ & $\begin{array}{l}\text { puna- } \\
\text { apila }\end{array}$ & $\begin{array}{l}\text { kevät- } \\
\text { rypsi }\end{array}$ & $\begin{array}{l}\text { syys- } \\
\text { vehnä }\end{array}$ & $\begin{array}{l}\text { syys- } \\
\text { vehnä } \\
\text { +puna- } \\
\text { apila }\end{array}$ & $\begin{array}{l}\text { puna- } \\
\text { apila }\end{array}$ & $\begin{array}{l}\text { kevät- } \\
\text { vehnä } \\
\text { +rainata }\end{array}$ \\
\hline 7 & $\begin{array}{l}\text { kevät- } \\
\text { vehnä } \\
\text { +puna- } \\
\text { apila }\end{array}$ & $\begin{array}{l}\text { puna- } \\
\text { apila }\end{array}$ & $\begin{array}{l}\text { kevät- } \\
\text { vehnä } \\
\text { +rainata }\end{array}$ & rainata & herne & $\begin{array}{l}\text { syys- } \\
\text { vehnä }\end{array}$ & $\begin{array}{l}\text { syys- } \\
\text { vehnä } \\
\text { +puna- } \\
\text { apila }\end{array}$ & $\begin{array}{l}\text { puna- } \\
\text { apila }\end{array}$ & $\begin{array}{l}\text { kevät- } \\
\text { rypsi }\end{array}$ & $\begin{array}{l}\text { syys- } \\
\text { vehnä }\end{array}$ & $\begin{array}{l}\text { syys- } \\
\text { vehnä } \\
\text { +puna- } \\
\text { apila }\end{array}$ \\
\hline 8 & $\begin{array}{l}\text { kevät- } \\
\text { rypsi }\end{array}$ & $\begin{array}{l}\text { syys- } \\
\text { vehnä }\end{array}$ & $\begin{array}{l}\text { syys- } \\
\text { vehnä } \\
\text { +puna- } \\
\text { apila } \\
\end{array}$ & $\begin{array}{l}\text { puna- } \\
\text { apila }\end{array}$ & $\begin{array}{l}\text { kevät- } \\
\text { vehnä } \\
\text { +rainata }\end{array}$ & rainata & herne & $\begin{array}{l}\text { syys- } \\
\text { vehnä }\end{array}$ & $\begin{array}{l}\text { syys- } \\
\text { vehnä } \\
\text { +puna- } \\
\text { apila } \\
\end{array}$ & $\begin{array}{l}\text { puna- } \\
\text { apila }\end{array}$ & $\begin{array}{l}\text { kevät- } \\
\text { rypsi }\end{array}$ \\
\hline 9 & $\begin{array}{l}\text { syys- } \\
\text { vehnä }\end{array}$ & $\begin{array}{l}\text { syys- } \\
\text { vehnä }\end{array}$ & $\begin{array}{l}\text { syys- } \\
\text { vehnä }\end{array}$ & $\begin{array}{l}\text { syys- } \\
\text { vehnä }\end{array}$ & $\begin{array}{l}\text { syys- } \\
\text { vehnä }\end{array}$ & $\begin{array}{l}\text { syys- } \\
\text { vehnä }\end{array}$ & $\begin{array}{l}\text { syys- } \\
\text { vehnä }\end{array}$ & $\begin{array}{l}\text { syys- } \\
\text { vehnä }\end{array}$ & $\begin{array}{l}\text { syys- } \\
\text { vehnä }\end{array}$ & $\begin{array}{l}\text { syys- } \\
\text { vehnä }\end{array}$ & $\begin{array}{l}\text { syys- } \\
\text { vehnä }\end{array}$ \\
\hline 10 & $\begin{array}{l}\text { kevät- } \\
\text { vehnä }\end{array}$ & $\begin{array}{l}\text { kevät- } \\
\text { vehnä }\end{array}$ & $\begin{array}{l}\text { kevät- } \\
\text { vehnä }\end{array}$ & $\begin{array}{l}\text { kevät- } \\
\text { vehnä }\end{array}$ & $\begin{array}{l}\text { kevät- } \\
\text { vehnä }\end{array}$ & $\begin{array}{l}\text { kevät- } \\
\text { vehnä }\end{array}$ & $\begin{array}{l}\text { kevät- } \\
\text { vehnä }\end{array}$ & $\begin{array}{l}\text { kevät- } \\
\text { vehnä }\end{array}$ & $\begin{array}{l}\text { kevät- } \\
\text { vehnä }\end{array}$ & $\begin{array}{l}\text { kevät- } \\
\text { vehnä }\end{array}$ & $\begin{array}{l}\text { kevät- } \\
\text { vehnä }\end{array}$ \\
\hline
\end{tabular}

\section{Tulokset ja tulosten tarkastelu}

Ensimmäinen koevuosi 2009 suosi herneen kasvua, satomäärä oli suurempi kuin kevätvehnän ja katetuotto 67 \% suurempi kevätvehnään nähden. Aluskasvien käyttö, sekä puna-apilan että rainadan, laskivat kevätvehnän satoa ja suhteellista kannattavuutta $6-10 \%$ kevätvehnän monokulttuuriin nähden. Kevätrypsin katetuotto A $16 \%$ pienempi kevätvehnän katetuottoa. Vuonna 2010 syysvehnän monokulttuuri antoi parhaan katetuoton. Kevätvehnän monokulttuuriin verrattuna katetuotto oli $35 \%$ suurempi. Kuivuudesta johtuen kevätvehnän ja herneen sadot olivat edellistä vuotta heikommat ja katetuotot alhaisemmat. Syysvehnän sato ja katetuotto laskivat aluskasvien käytöstä. Syysviljojen myöhäisestä kylvöstä johtuen herneen ja kevätrypsin suotuisa esikasvivaikutus ei tullut näkyviin sadon määrän kasvuna. Kevätrypsin jälkeen kylvetyn syysvehnä katetuotto A oli $10 \%$ syysvehnän monokulttuuria alhaisempi. Herneellä tuli selvästi esiin satomäärän suuren vaihtelun heijastuminen sen viljelyn kannattavuuteen. Herneellä kate A oli $57 \%$ pienempi syysvehnän katetuottoa.

Vuonna 2011 syysvehnän monokulttuurin negatiiviset vaikutukset alkoivat näkyä vehnäsadossa. Yksipuolisessa viljelyssä syysvehnällä tyvitauteja aiheuttavat sienet saattavat tulla merkittäväksi satoa rajoittavaksi tekijäksi, mikä korostuu etenkin suorakylvössä ja kevytmuokkauksessa, jossa taudinaiheuttajille jää suora yhteys siirtyä seuraavaan kasvustoon. Tästä on osoituksena lakoutumisen ja erityisesti talvituhojen 
merkittävä lisääntyminen yksipuolisessa syysvehnän viljelyssä. Talvituhot olivat vuonna 2011 syysvehnän monokulttuurissa $23 \%$ kun taas kevätrypsin jälkeen viljeltynä $0 \%$. Syysvehnäsato oli vastaavasti $38 \%$ pienempi syysvehnän jälkeen, kuin kevätrypsin jälkeen. Osan kevätrypsin jälkeen viljellyn syysvehnän sadosta selittänee myös esikasvin lannoitus, josta käyttämätöntä typpeä on mahdollisesti jäänyt syysvehnän hyväksi. Puna-apilan jälkeen syysvehnäsato oli $30 \%$ ja herneen jälkeen $23 \%$ monokulttuurisyysvehnää suurempi. Syysvehnä sato jäi myös kevätvehnän jatkuvan viljelynsatoa $21 \%$ alhaisemmaksi. Yksipuolisessa syysvehnän viljelyssä tuhannen siemenen painot jäivät jopa $10 \%$ pienemmiksi ja hehtolitrapaino 2-2,5 $\mathrm{kg}$ alle muiden syysvehnien arvojen. Hehtolitrapainojen kohdalla tämä merkitsisi sadon täyttävän vain rehuviljan vastaanottovaatimukset. Toisaalta vuoden vaihteessa 2011/2012 mylly- ja rehuvehnien hintaerot olivat kutistuneet olemattomiin. Monokulttuuri kevätvehnän katetuottoa paremman katetuotto A:n antoi kevätrypsin jälkeen viljelty syysvehnä $+18 \%$ ja puna-apilan jälkeen viljelty syysvehnä $+9 \%$, muilla viljakasveilla katetuotto A jäi pienemmäksi, herneellä - $23 \%$ ja syysvehnän monokulttuurilla - $28 \%$.

Kolmen koevuoden jälkeen yksipuolisen syysvehnän viljelyn kate A oli kevätvehnän jatkuvan viljelyn katetuottoa $2 \%$ parempi. Syysviljojen paremman kuivuuden kestävyyden johdosta syysvehnän satotasot ovat Lounais-Suomen savialueilla kevätvehnien satoa korkeampia. Korkeammasta satotasosta johtuen syysvehnän valkuaispitoisuus jää alle myllyvehnien laatuvaatimuksen kevätvehniä useammin ilman tähkän täyttymisvaiheessa annettavaa lisätyppilannoitusta. Kiertoon 1 kuuluvien koejäsenten 1-4 keskimääräinen kate A oli $9 \%$ pienempi ja kiertoon 2 kuluvien koejäsenten 5-8 kate A $7 \%$ pienempi jatkuvan syysvehnäkierron kolmen vuoden yhteenlasketuista katetuotoista.

Koska koesarjassa ei ole vielä umpeutunut viiden vuoden kierto ja satotasot eivät ole hakeutuneet vielä kohdilleen, tulevat vasta koesarjan viimeiset vuodet osoittamaan järjestelmien väliset todelliset erot.

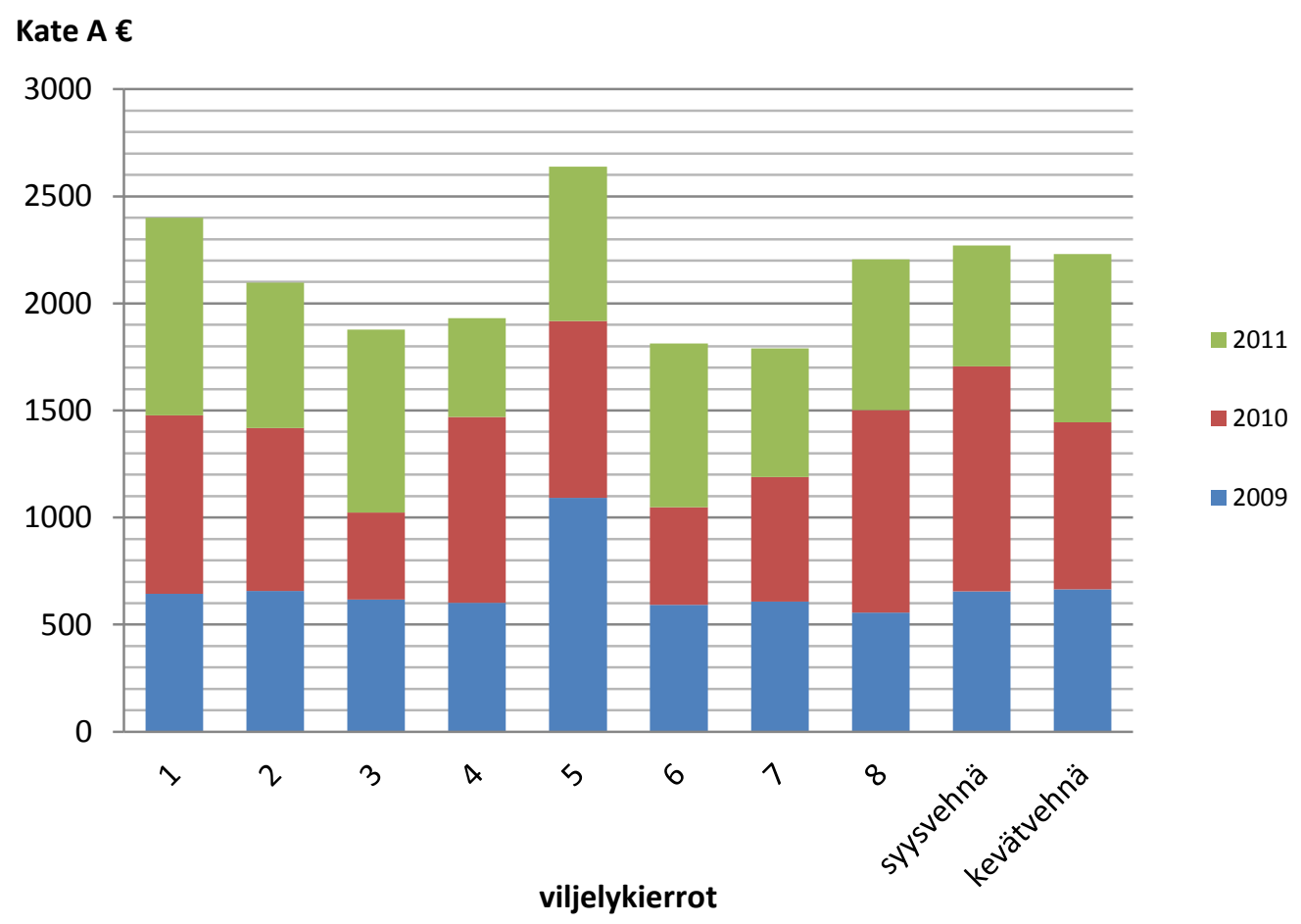

Kuva 1. Viljelykiertojen yhteenlaskettu suhteellinen kannattavuus 2009-2011 verrattuna jatkuvaan syysvehnän viljelyyn. Kiertojen numerokoodien selitykset taulukossa 1. 